\title{
Article
}

\section{Transport Systems and Mobility for Smart Cities}

\author{
Paulo Ribeiro *(1), Gabriel Dias (1) and Paulo Pereira \\ Centre for Territory Environment and Construction, School of Engineering, University of Minho, \\ 4800-058 Guimarães, Portugal; id8651@alunos.uminho.pt (G.D.); ppereira@civil.uminho.pt (P.P.) \\ * Correspondence: pauloribeiro@civil.uminho.pt
}

\section{check for}

updates

Citation: Ribeiro, P.; Dias, G.; Pereira P. Transport Systems and Mobility for Smart Cities. Appl. Syst. Innov. 2021, 4, 61. https://doi.org/10.3390/ asi4030061

Academic Editor: Teen-Hang Meen

Received: 12 July 2021

Accepted: 27 August 2021

Published: 3 September 2021

Publisher's Note: MDPI stays neutral with regard to jurisdictional claims in published maps and institutional affiliations.

Copyright: (c) 2021 by the authors. Licensee MDPI, Basel, Switzerland. This article is an open access article distributed under the terms and conditions of the Creative Commons Attribution (CC BY) license (https:/ / creativecommons.org/licenses/by/ $4.0 /)$.

\begin{abstract}
Nowadays, cities appear to be the best place to live, attracting more and more people and activities. However, not only does this movement represent a threat to the environment but also provides challenges and opportunities for everyone, e.g., people, companies, organizations, and governments. To provide a good urban quality of life, the efficiency of all assets, buildings, infrastructures, and all systems, as well as taking care of the natural environment, must be addressed and achieved. This paper will, therefore, present the available literature on the subject to discuss the present context, the main challenges, as well as the concept of smart cities, with future cities relying on the mobility and evolution of transport systems for smart, sustainable, resilient, and inclusive mobility. As a result of the research, it is possible to infer that an integrated smart mobility approach can support the efficiency of all transport networks for everyone, today and tomorrow, while faced with the threat of climate change and the challenges of citizens.
\end{abstract}

Keywords: smart cities; buildings; transportation; citizens; digital information; governance; mobility

\section{Introduction}

In our modern history, cities have become the best place to live, attracting more and more people and activities, where new knowledge, creativity, and innovation have been the fuel of our world. Given their characteristics, cities have always been the ideal places for creativity and innovation, as is obvious in these three examples: (a) Etruscan engineers built the Cloaca Maxima in Rome around 600 B.C., which is a fascinating public sewage system that required planning, technique, and vision; (b) Vitruvius, in his architecture treatise De Architectura (I.B.C.), provided details, among many other guiding principles, for building projects and how the special purposes of different rooms require different exposures; (c) Renaissance Florence was a place of extraordinary creativity in the arts and architecture.

Additionally, global populations have been continually on a sharp rise, with $70 \%$ of the world's population predicted to be living in cities by 2050 [1], making cities critical to achieving a sustainable future for the world. However, this movement represents a threat to the environment, with challenges and opportunities for everyone, including people, companies, organisations, and governments, with the final objective of offering a better quality of life for everyone. This is why the United Nations has established its 2030 Agenda for Sustainable Development [2] with 17 Sustainable Development Goals, including SDG 11: Sustainable Cities and Communities: Making cities and human settlements inclusive, safe, resilient, and sustainable. As in the past, the evolution of cities will need to be supported by new knowledge and technological evolution. However, when looking at the present situation with great global inequalities, the focus on "smart cities" must integrate the equilibrium between nature and the physical environment, and the education of citizens, promoting more inclusive, tolerant, and open cities.

This is translated into the concept of the "smart city", which has been evolving and attempts to provide answers to a more comprehensive vision such as that of the United Nations 2030 Agenda, in particular, Sustainable Development Goal SGD 11 [2]. Starting 
with inclusiveness and safety, the UN vision places the focus on people, assuming that cities, in all their components, must be sustainable and offer a quality of life for today's and tomorrow's citizens as well as preparing for unattended, but possibly simulated, extreme events that happen over the life cycle of all built environments, and also considering the natural environment. Therefore, in every context, the nuclear question for cities is the identification of the needs of its citizens and also ensuring their engagement in the process of building "Smart and Liveable Cities" where sustainable development will only be possible by way of the integration and convergence of digital and physical infrastructures with the participation of citizens.

Thus, one important aim of smart city development is to provide a sound and reliably built environment for citizens, which includes buildings, transport infrastructures, and urban infrastructures that deliver an efficient service, save time and money, and have as a result: (a) an increase in productivity and competitiveness; (b) a reduction in the environmental impact; (c) better welfare for its citizens.

As the transportation system in cities is closely related to all of these three results, this research work aims at characterizing the main aspects of smart cities and showing the role of transportation systems in maximizing the benefits brought to cities by the implementation of technology, which could be replicated in many cities around the world. In addition, this research discusses the importance of smart cities in achieving and promoting the three pillars of sustainability (environmental, economic, and social).

For this, the research starts with a literature review, where the components of smart cities are explained, followed by the characterization of transportation systems in smart cities, and a discussion about this theme, which highlights the importance of technology in transportation systems and the use of MaaS to promote sustainable and efficient journeys in the city. Finally, the conclusion from the research is outlined.

\section{Literature Review}

Today, smart, sustainable, resilient, and liveable cities are buzz words adopted to underline better places to live, where these concepts present different meanings for different stakeholders. Firstly, to contribute to a common focus, cities and territories should be considered as a "living organism": they are born, grow, renovate, rehabilitate, die, and are born again, with new entities and new faces for the welcoming of new activities. It is undoubtedly the case that, around the world, the main focus has been placed on the concept of the "smart city", which is assumed to be a technology-based system with the flow of data obtained through global sensorization, and the production of information feeding an information system supported by major data analytics and artificial intelligence, with several interconnected layers corresponding to the different components of a city environment (Figure 1). Ultimately, this system should support policymakers in their duty regarding city governance, as well as citizens' decisions.

Concerning the analysis of the diverse concepts for a future city, the right question should be asked: what would a good city to live in be like, for everyone today and tomorrow? This city should be competitive, attracting new companies and institutions, offering high qualified jobs, attracting new talents, led by sound and trustful governance, and, in the end, producing wealth for everyone with respect for nature. The competitiveness of the city will also depend on its efficiency, including the sustainable and resilient management of the built environment, a heritage to take care of, the city's systems and services, assuming responsibility for the present and future challenges and threats, and also offering fluid mobility for people and goods. The competitive city should be pleasant and healthy, and mindful of the natural environment, where the equilibrium between the city and the surrounding territory will be a permanent duty of the government. The competitive and efficient city will require a digital transformation as an essential project to connect everything and everyone, without forgetting the cybersecurity of systems and people. 


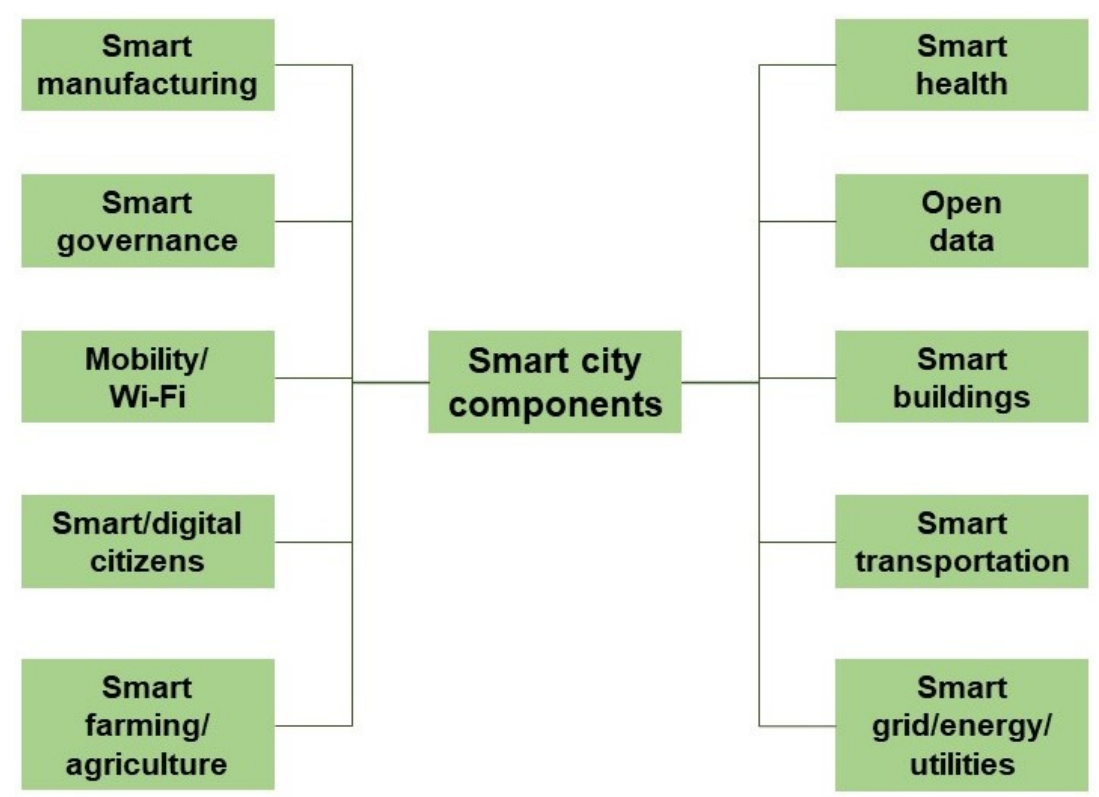

Figure 1. Components of a smart city. Source: Adapted from Reddy et al. (2018) [3].

Governance should be carried out by city authorities in an integrated manner with companies, research and technological institutions, and all citizens in an inclusive way with governments having the irreplaceable duty of constructing and maintaining leadership to achieve the vision of a competitive, liveable city. All citizens, who are the last element, will be able to participate in the construction of the visions of their city inclusively, from the youngest to the oldest generations.

\subsection{Built Environment: The Contribution for an Efficient Competitive City}

A sound and reliably built environment can only be possible by making the best use of materials and technology, as well as Intelligent Transport System (ITS), with the contribution of users, but always taking into consideration the Life Cycle Assessment (LCA) approach, not only during the use phase of the built environment but obligatorily integrating the embodied energy required during all processes, from extraction to rehabilitation.

In the future, the construction sector will be a service-oriented business, with a usercentric approach offering flexible and connected spaces, and inclusive cities with a high quality of life for all citizens [4]. Clean energy buildings, which are about much more than saving energy, should be built with enhanced materials, increased durability and reusability, increased occupant comfort, quality of life, and productivity with the potential to integrate renewable, storage, and digital technologies, and to link buildings with their surroundings, especially the transport system.

Unfortunately, buildings today are big and inefficient energy consumers: responsible for more than $33 \%$ of energy consumption; they produce $32 \%$ GHG and $20 \%$ of waste energy. Thus, the optimization of energy consumption is a priority under the evolution of zero impact built environments supported by the European strategy "40-27-27", which has set the target by 2030 of controlling global warming: with a reduction of $40 \%$ of GHG emission (reference to1990), supported by $27 \%$ increase in renewable energy, and a $27 \%$ increase in energy efficiency. A big challenge in saving energy in buildings today is being adopted through the so-called zero energy buildings (ZEBs), achievable by reducing the energy demands of the building and by exploiting renewable energy sources (RES) using appropriate technologies [5].

The transport sector is one of the major drivers for economic growth and its role in every aspect of society cannot be overstated. An efficient and effective transport system 
not only supports the economy with the movement of people and goods but its influence is much deeper, having a major impact on the environment and communities.

The future of transport is oriented towards the development of systems more focused on the citizens, ensuring accessibility and inclusiveness (an increase in the activities of elderly and younger people in multimodal patterns) while reducing the environmental impact and pollution, in particular, improving the quality of life of cities. Walking and cycling will also continue to have a greater presence in cities and urban planning, reclaiming the reshaping of the urban landscape. The required integration between transport infrastructure and digital technologies will create an intelligent infrastructure allowing for the collection and analysis of data in real-time, providing increased operational efficiency for infrastructure, as well as for mobility. Autonomous vehicles will create more available free space in cities that can be used for other purposes and opening additional possibilities for upgrading transport infrastructures. Finally, an efficient asset management process is needed to ensure cost-effectiveness in the planning, design, delivery, operation, and maintenance of large infrastructures and networks, by adopting risk-based approaches and network resilience perspectives to be considered throughout the lifecycle.

\subsection{Environmental Quality}

Human activities are the main predators of the environment, and make a clear contribution to the threats to the quality of the life of citizens. In a simplified way, it is possible to state that housing, transportation, and industry equally share energy consumption as well as pollution production. Each year in Europe, pollution and traffic congestion account for: $10 \%$ of premature deaths (urban traffic is responsible for $50 \%$ ), with a severe reduction in life expectancy; 100,000 fatalities; 20 million people with respiratory problems; a reduction in productivity, with a loss of 725,000 years of activity; economic impact as large as EUR 183 per $\mathrm{km}$ (2.9\% GDP; transport contributing to $1.0 \% \mathrm{GDP})$; noise (>85 dBA) and being responsible for severe health problems.

Concerning buildings and infrastructures, we are far from reaching our goals of energy reduction and, consequently, far from the reduction of pollution. This includes the adoption of ZEB buildings and the concept and practice of a circular economy for any type of built environment. Regarding the evolution of mobility tendencies, with an increase in active modes, and with transport systems more focused on citizens, ensuring accessibility and inclusiveness, fostering an increase in walking and cycling, and the environmental quality of cities should be a major concern. It is a fact that the levels of physical activity and caloric expenditure, as well as the health benefits, are far greater for cyclists; however, exposure to noise and $\mathrm{NO}_{2}$ is significantly greater for cyclists than for motorists [6], outweighing the benefits of these activities.

When discussing the environmental quality of a city, this fact should be considered: today, for the majority of cities, it is difficult to identify city borders, being easier to talk about a metropolitan area. All cities depend on the surrounding territory. That is why an inclusive approach should look at the benefits of tackling the challenges presented to cities as a unified metro region, as well as through the integration of cities with forests, including three categories: "inner", "nearby", and "faraway" forests. This approach will effectively combat climate change, protect watersheds and biodiversity, and improve human wellbeing.

\subsection{Digital Transformation, Citizens and Governance}

The development of advanced sensing [7] information and communications systems, creating an intelligent city network, is a prerequisite for and a crucial key element of smart cities, feeding an evaluation and modelling system, and able to control several parameters for more efficient management of the city. This system is obligatory to support the governance of a city in the control of the quality of life, as well as for the implementation of measures towards the reduction of environmental and health impacts. In this context, 
a smart grid will also allow cities to manage energy demands, protect the distribution network, save energy, and reduce costs.

The digital transformation of cities will allow for the integration of intelligence in the physical environment through embedded electronic and digital systems in buildings and infrastructures. This will result in millions of small disposable devices (IoTs), each one able to capture a physical aspect of the environment and endowed with wireless communication capabilities [8]. This provides a rich analytical context, highlighting the need to store and process vast amounts of heterogeneous data flowing at different velocities. This data is defined as Big Data, which imposes significant difficulties on traditional data techniques and technologies.

However, the question is: in this complex process, what is the role of citizens? All the achievements, at last, will be in place to benefit their quality of life. However, it is certain that citizens will only participate actively as data providers and end-users when they feel prepared through adequate digital literacy and involved in all processes. By defining their needs, and finally feeling confident in IoT, they will promote the potential of smart technology. That is why city governance, being an enormously complex process, with the multifaceted and multilevel ecosystem of various agencies and stakeholder groups (governments, companies, citizens), will assume an irreplaceable role, including the solution of conflicting interests. As a result, smart cities require a proper governance system to connect all forces at work, allowing for knowledge transfers that facilitate decision making to maximize their socioeconomic and environmental performance [9].

\subsection{Mobility and Transportation Systems: Present Challenges}

The transportation ecosystem is becoming increasingly complex, particularly in big cities with a huge increase in transport demand implying urban mobility that is dominated by private cars. This results in an increase in road traffic and causes problems in mobility such as congestion, environmental pollution, noise, and traffic accidents, which directly affect the quality of the urban mobility services and reduce the levels of accessibility and urban mobility. Additionally, this contributes to increased delays and energy expenditure, pollution, and stress, which in turn decrease productivity and lead to higher living costs for society. Car accidents remain one of the biggest concerns. In the EU-28, these account for more than 20,000 fatalities and 100,000 serious injuries every year [10].

Mobility flows are a proxy for understanding human activity in urban space, playing the role of a prime driver for sustainability, as well as the main integrator of the flow of objects and people, and also supporting the flow of information. The nuclear duty of the transport system is, therefore, to provide timely and safe mobility under environmental protection, to assume new methods of mobility, and to integrate different users' expectations and evolution-particularly for the young, elderly, and less able people who are considered the most vulnerable road users (VRUs). In addition, the transport system must make the transition to mixed traffic environments with the coexistence of present and future connected and automated vehicles (CAVs). The introduction of CAVs is regarded as crucial by the European Commission to achieve the 2050 goals of reducing GHG emissions by $60 \%$ and, in line with Vision Zero, to have close to zero fatalities in transportation [11].

Nevertheless, it has become clear that the positive impact that CAVs can bring for sustainability and safety will have to first withstand the challenges of coexistence with conventional modes of transportation and the challenge of transitioning to mixed traffic environments including both "acceptance, trust and reliance on automation" and "the role of humans in emergencies [12].

Concerning the support to meet any challenges, the focus is placed on having relevant and updated data and information. Thus, in addition to the rising data acquisition capacity and intelligence of vehicles, the development of a global system of sensorization in transport and mobility infrastructure components is essential through innovative digital technologies, used in a multidisciplinary environment, and including mobile technology, in order to observe all types of movements of vehicles and people, and to consider the 
users. This system will need to capture relevant data supporting the production of essential information to support the integrated management of the mobility system, as well as to give answers to the global decisions on the city environment (noise, air quality). The information produced can also support the development of key performance indicators that support decision making in several fields, focused on the current mobility operation and optimizing the global mobility and transport system, as well as developing alerts under scenarios of severe and unpredicted threats.

Mobility relies on users, vehicles, and transport infrastructures where different threats that can cause disruption should be considered, such as natural disasters (hurricanes, floods, fires) or human-made events such as terrorist attacks, cultural events, strikes, and systems failures caused by human error or mismanagement. Thus, the resilience of the transportation system should be carefully analysed to test its capacity to absorb and/or reduce impacts of different disturbances as well as the capacity to maintain and/or restore its normal operation to an acceptable performance level within a timeframe and cost that are considered acceptable $[13,14]$.

In a longer time frame, the digitization of transport promises to lead towards fully personalized services and commercial offers. Despite this, an important and often overlooked aspect exists regarding the impact of users and their ability and readiness to take advantage of the new opportunities. Under a "building capacity" approach, users would understand the global process of data capture, treatment, and the production of information so that they would put their trust in data governance, also allowing for openness to share their data. Different users should be considered to allow an equal capacity to understand the new features of mobility management and participation in the evolving process. Urban Living Labs would be considered in the process as a robust and efficient approach to constitute an arena for experimentation and innovation with participation in the experimentation of new technology, devices, and systems.

\section{Methodology}

This research work is composed from the scientific literature, as well as the grey literature from renowned institutions surrounding the theme of smart cities and transportation systems in this type of built environment. To collect the information presented in this paper, databases such as Web of Science, Scopus, and Google were used. The literature collection was composed of four different phases [15]. The first was composed of a comprehensive literature gathering, followed by the application of general keywords related to the research theme, such as smart cities, transportation systems in smart cities, mobility and transportation systems, and digital transformation. Phase 3 was composed of the incorporation of literature from renowned institutions. Phase 4 was composed of the narrowing of the relevant literature to be used in this paper.

All the information retrieved in these four phases was used to explain and characterize the concept of smart cities and to show how to operationalize this concept combined with transportation systems in cities all around the world. In addition, a discussion was performed to debate the theme, and to provide a better understanding of the subject presented in this paper.

In order to include the transport models for smart cities, the research work also defined an integrated mobility and transport system, which must address four key dimensions: (i) transport modes (motorized and nonmotorized); (ii) territories (city centres and peri-urban areas); (iii) people (young, active, and VRU); (iv) digitization (Mobility as a Service (MaaS) and digital platforms), to promote equity, cohesion, and sustainability across smart cities. There is a widespread idea that transport systems are increasingly being integrated into all territories as digitization takes its course, increasingly reshaping landscapes, reconfiguring boundaries, and altering the way people live and experience the territories. The concepts of smart cities rely heavily on the idea that digitization can be a powerful driving force for building new modes of sensing and experiencing local spaces, by simultaneously facilitating physical and virtual mobilities across different and 
geographically distant places. The extensive literature [16] has provided evidence about the positive effects of digitization in territories, while it also brings about new important challenges concerning social diversity.

Despite the fact that integrated transport systems are the main building block of governance models in more recent trends and are strongly emphasized in policy programs, territories are still revealing great disparities with regards to the actual degree of that integration. For many different reasons, living in or nearby the city centre still represents the best life chances, including the ability to take advantage of the digitization potentialities. Large numbers of people are kept apart from the life of city centres, as well as many other places, by poor access to services of all kinds due to poor access to transportation. Thus, an integrated approach to mobility aims to provide accessibility to all transportation modes providing the necessary conceptual and practical tools for the better inclusion of people according to a set of socioeconomic variables.

Therefore, it is necessary to study and explore, together with innovative methodologies, the challenges of cities and low-density territories, analysing the conditions in which digitization can be potentiated and used for capitalizing on resources of a different nature that contribute to maintain and revitalize local spaces. These territories can increase their attractiveness as places to live by promoting integrative, safe, and trustful transport systems by which citizens, from all social strata can fully perform their demands and expectations of mobility.

Figure 2 presents a schematic representation of different transportation networks linking the city and its surroundings, and enhancing the need for the integration of transport and land use to promote balanced, efficient, inclusive, and safe mobility. This mobility should be supported by public transit and other more sustainable modes of transport, reducing the externalities of mobility and people and goods, while promoting quality of life and wellbeing for all.

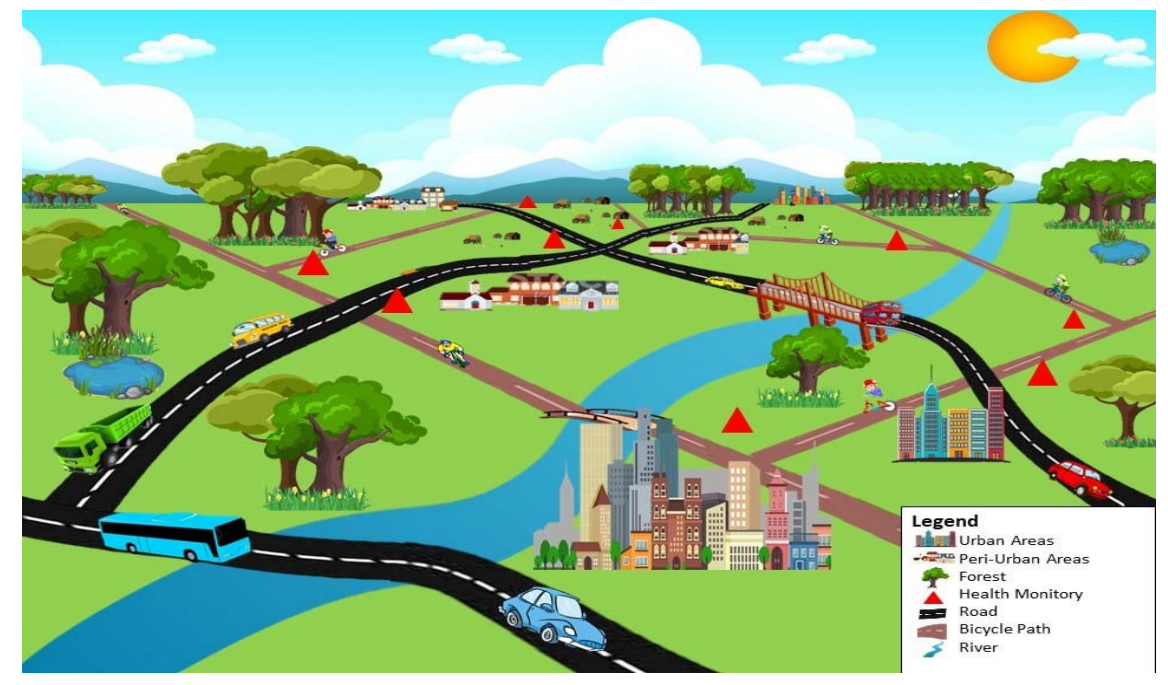

Figure 2. An integrated mobility and transport system. Source: Authors.

A new approach to urban mobility policy is needed where accessibility is the objective and mobility is the instrument (Figure 3). It is also necessary to reorganize mobility to accommodate the radical changes brought about by the market and industry. On the other hand, it is important to integrate a cultural change, i.e., real vs virtual world (aspirations, ambitions), and the logic of new generations (from ownership to use). Thus, it is urgent to change the new paradigm of mobility through the introduction of (i) shared mobility systems; (ii) real-time, customized information; (iii) mobility as an instrumental system of accessibility; (iv) mobility and land use with a functional orientation and a strong focus on people. 


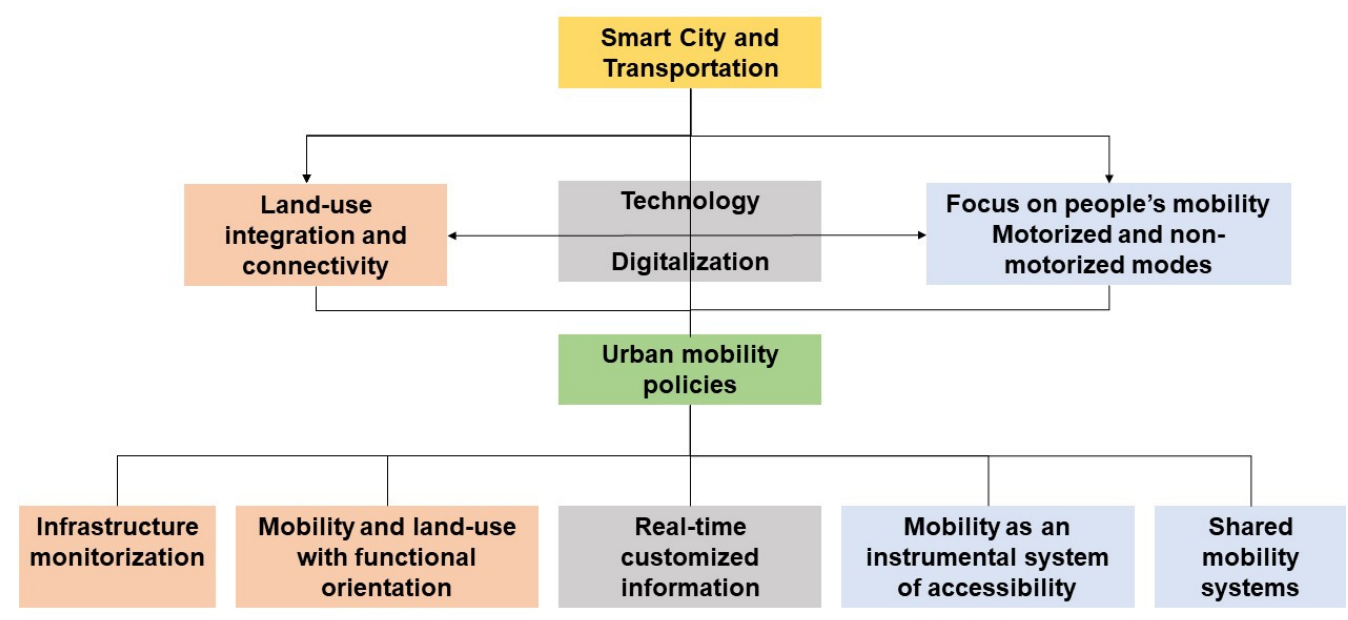

Figure 3. New approach to urban mobility policy. Source: Authors.

\section{Discussion}

There is no doubt that citizens should be the main beneficiaries of new mobility services through the adoption of the concept of Mobility as a Service (MaaS). However, there is not a clear vision about the strategies, impacts, and efficiency of these new mobility services related to alternative transportation modes, namely in reducing traffic congestion without having to build new infrastructures (roads, tunnels, and light rail). Among several possible definitions, based on Helsinki's vision [17], MaaS is a smart user-centric model of the distribution of information and transportation procurement in which all transport providers are aggregated with a single mobility provider-MaaS operator-that provides services to the user through a single digital platform.

MaaS represents a strong value proposition supported by the diversity of travel options and, in terms of the capabilities of the system, are characterized by trip planning, easy transactions, flexible payments, dynamic trip management, and a personalized and customized service. MaaS strategies would allow citizens to choose between public and private transport providers and would be among the fastest and cheapest ways of travelling, according to their needs, at any time.

According to this concept, a mobility system would provide dynamic bus routes based on the current demands at any time. The system would also be accessible through mobile devices (e.g., smartphones) to plan and pay for trips for all types of purposes that could accomplish a diversity of travelling options: rideshare (carpooling), an on-demand bus, an automated car, or traditional public transports (buses, metro, train, among others) [18].

The adoption and implementation of MaaS would therefore trigger a new paradigm in mobility integrating several changes: (i) from mobility to accessibility; (ii) from city to the metropolitan areas; (iii) from service regulation to activity regulation (safety, quality, capability); (iv) from ownership to use; (v) from data confidentiality to the sharing of the use of the data; (vi) from subsidizing companies to subsidizing citizens; (vii) from public transport to an entire mobility system centred on public transport; (viii) to a culture of accessibility and quality of life. New mobility systems show that a set of characteristics, needs, obstacles, and user requirements, often related to sociocultural variables such as age, gender, and social class, must be studied to provide recommendations for policymakers to design an inclusive digital transport system that is integrated and equitable [19].

To achieve integrated, intelligent, inclusive, and safe mobility, a set of key factors concerning people, territory, transport systems, and digital interconnected solutions must be addressed, identified, studied, and analysed such as (i) people (sociodemographic characteristics, social and economic vulnerability, needs and digital competences concerning mobility and transportation); (ii) territory (development level, forms of administration/governance in the sector of activity, historical and political key features for urban areas); (iii) transport systems (supply and demand of all types of transportation modes and 
their degree of social inclusiveness and digitization); (iv) digital interconnected solutions (digital innovations and their ability to respond to societal needs and expectations that can bootstrap innovative, efficient, and better transports for the urban and peri-urban areas).

With inclusive, digitally-interconnected transportation, people can be active agents of territorial development and can take advantage of digitization, therefore contributing to a reduction of the tendency to depopulate rural territories and to an increase in inclusion and opportunities for all [20]. Thus, working with people to identify their usages and needs concerning digital solutions, and the design of digital tools that contribute to developing forms of mobility will enhance social cohesion, foster sustainability, and augment quality of life. The accomplishment of integrated, intelligent, inclusive and safe mobility, supported by a digitally interconnected transportation system, requires an integrated multidimensional analysis about the digitization trends in transport systems, together with citizen's views, needs, and expectations, and with the support of governance and regulatory transportation models, which integrate all mobility players, including transport companies.

Thus, a global solution for such a new mobility approach, integrating different transportation networks and modes, as well as the characteristics of people, should include the following steps: (a) analysis of the characteristics of the transportation networks (motorized and nonmotorized); (b) analysis of the features of different transportation modes with the objective of optimising their mobility capacity; (c) identification of the different needs and expectations of citizens according to their social characteristics, including their level of digital literacy; (d) development of innovative digital solutions that meet the diversity of citizens' demands under co-creation methodologies; (e) promotion of the engagement of people in the adoption and appropriation of digital solutions through the development of experiences in a living lab context; (f) development of recommendations for policymakers and practical applications for designing an inclusive digital transport system in all types of territories, which include the views of all mobility players, in particular the transport companies; ( $g$ ) development and communicative implementation strategies in order to reach public awareness about a new mobility approach, so as to promote the optimisation of mobility for all.

\section{Conclusions}

The concept of smart cities is assumed as a technology-based system built on the acquisition of data through global sensorization with the production of information feeding an information system that is supported by big data analytics and artificial intelligence with several interconnected layers, corresponding to the different components of a city's environment. The global objective is that of building "smart and liveable cities" where sustainable development will only be possible by way of the integration and convergence of digital and physical infrastructures with the participation of citizens and supporting the policymakers in their duty of city governance. The accomplishment of such a global challenge will only be possible when a reliably built environment is coupled with an intelligent city network, this being a prerequisite of smart cities.

The accomplishment of integrated, intelligent, inclusive and safe mobility, supported by digitally interconnected transportation, requires an integrated multidimensional approach considering four key dimensions: (i) transport modes (motorized and nonmotorized); (ii) territories (cities centres and peri-urban areas); (iii) people (young, active, and VRU); (iv) digitization (MaaS and digital platforms), in order to promote equity, cohesion, and sustainability across smart cities. In particular, the approach should include the current digitization trends in transport systems together with citizen's views, needs, and expectations, and the support of governance transportation models that integrate all mobility players, including transport companies.

The integrated multimodal transportation systems achieved by the use of technology in smart cities can be replicated in cities all around the world by the implementation of departments of transportation that work closely to the needs of people and that integrate technology to help them manage the system to better meet the needs of the users. 
In short, the success of smart cities is linked to the reorganization of the transportation systems, which can be a great asset to cities to achieve sustainability through the implementation of technology that allows the planning of routes for all types of purposes and to achieve diversity in travelling options according to the needs of the users, such as carpooling, on-demand bus lines, automated cars, shared micromobility, and traditional public transports (buses, metro, among others).

Author Contributions: Conceptualization, P.R. and P.P.; Data curation, P.R., G.D. and P.P.; Investigation, P.R., G.D. and P.R.; Methodology, P.R., G.D. and P.P.; Supervision, P.P.; Writing original draft, P.R. and P.P., Writing-review and editing, G.D. All authors have read and agreed to the published version of the manuscript.

Funding: This research received no external funding.

Institutional Review Board Statement: Not applicable.

Informed Consent Statement: Not applicable.

Data Availability Statement: The data presented in this study are available on request from the corresponding author. The data are not publicly available due to privacy.

Acknowledgments: The authors acknowledge the UMCidades and CTAC support.

Conflicts of Interest: The authors declare no conflict of interest. The funders had no role in the design of the study; in the collection, analyses, or interpretation of the data; in the writing of the manuscript, or in the decision to publish the results.

\section{References}

1. United Nations. Revision of World Urbanization Prospects. 2018. Available online: https://population.un.org/wup (accessed on 22 May 2019).

2. United Nations. Transforming our World: The 2030 Agenda for Sustainable Development. 2015. Available online: https: / / sustainabledevelopment.un.org/ post2015/transformingourworld (accessed on 17 June 2021).

3. Reddy, A.G.; Suresh, D.; Phaneendra, K.; Shin, J.S.; Odelu, V. Provably secure pseudo-identity based device authentication for smart cities environment. Sustain. Cities Soc. 2018, 41, 878-885. [CrossRef]

4. ECTP. The High-Tech Building Industry in Support of the EU Energy, Climate and Sustainability Objectives: Towards a Generalised European Low-Carbon \& Resilient Built Environment. ECTP FP9 Position Paper, European Construction, Built ENVIRONMENT and Energy-Efficient Building Technology Platform. 2018. Available online: http://www.ectp.org/resources/ publications (accessed on 17 June 2021).

5. Kylili, A.; Fokaides, P.A. European smart cities: The role of zero energy buildings. Sustain. Cities Soc. 2015, 15, 86-95. [CrossRef]

6. Apparicio, P.; Gelb, J.; Carrier, M.; Mathieu, M.-Ë.; Kingham, S. Exposure to noise and air pollution by mode of transportation during rush hours in Montreal. J. Transp. Geogr. 2018, 70, 182-192. [CrossRef]

7. Weng, T.; Agarwal, Y. From Buildings to Smart Buildings-Sensing and Actuation to Improve Energy Efficiency. IEEE Des. Test Comput. 2012, 29, 36-44. [CrossRef]

8. Martins, R.; Santos, H.; Rebelo, J.; Ferreira, L. EDGE4ALL_Edge Platform for Smart City; The Smart City Summit Demos 2018; European Union Digital Library: Guimarães, Portugal, 2018. [CrossRef]

9. Ruhlandt, R.W.S. The governance of smart cities: A systematic literature review. Cities 2018, 81, 1-23. [CrossRef]

10. European Commission. Press Release on "2016 Road Safety Statistics" European Commission. 2017. Available online: http: / / europa.eu/rapid/press-release_MEMO-17-675_en.htm (accessed on 26 June 2018).

11. European Commission. A Roadmap for Moving to a Competitive Low Carbon Economy in 2050; Publications Office of the European Union: Brussels, Belgium, 2011.

12. Kyriakidis, M.; de Winter, J.C.F.; Stanton, N.; Bellet, T.; van Arem, B.; Brookhuis, K.; Martens, M.H.; Bengler, K.; Andersson, J.; Merat, N.; et al. A human factors perspective on automated driving. Theor. Issues Ergon. Sci. 2019, 20, 223-249. [CrossRef]

13. Wan, C.; Yang, Z.; Zhang, D.; Yan, X.; Fan, S. Resilience in transportation systems: A systematic review and future directions. Transp. Rev. 2018, 38, 479-498. [CrossRef]

14. Gonçalves, L.A.P.J.; Ribeiro, P.J.G. Resilience of urban transportation systems. Concept, characteristics, and methods. J. Transp. Geogr. 2020, 85, 102727. [CrossRef]

15. Dias, G.; Arsenio, E.; Ribeiro, P. The Role of Shared E-Scooter Systems in Urban Sustainability and Resilience during the Covid-19 Mobility Restrictions. Sustainability 2021, 13, 7084. [CrossRef]

16. Bilbao-Osorio, B.; Dutta, S.; Lanvin, B. The Global Information Technology Report 2013: Growth and Jobs in a Hyperconnected World; World Economic Forum and INSEAD: Geneva, Switzerland, 2013.

17. MaaS Global. Mobility as a Service. MaaS Global. 2019. Available online: https://maas.global (accessed on 25 June 2019). 
18. Eggers, W.D. Delivering on Digital: The Innovators and Technologies that are Transforming Government; Rosetta Books: New York, NY, USA, 2016

19. Eppenberger, N.; Richter, M.A. The opportunity of shared autonomous vehicles to improve spatial equity in accessibility and socio-economic developments in European urban areas. Eur. Transp. Res. Rev. 2021, 13, 1-21. [CrossRef]

20. Wang, C.; Steinfeld, E.; Maisel, J.; Kang, B. Is your smart city inclusive? Evaluating proposals from the U.S. Department of Transportation's smart city challenge. Sustain. Cities Soc. 2021, 74, 103148. [CrossRef] 